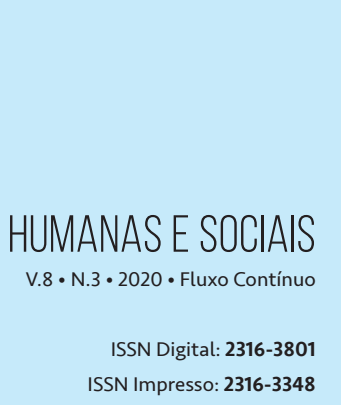

DOI: 10.17564/2316-3801.2020v8n3p101-120
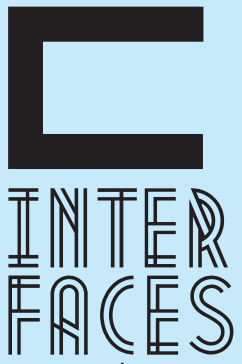

CIENTIIFICAS

\title{
ESPAÇO FEMININO NO DISCURSO DO PRESIDENTE
}

\section{FEMININE SPACE IN THE SPEECH OF PRESIDENT}

\section{ESPACIO FEMENINO EM EL DISCURSO DEL PRESIDENT}

\section{RESUMO}

Trata-se da análise do discurso proferido pelo presidente, em homenagem ao Dia Internacional da Mulher, no ano de 2017, com escopo de verificar estratégias de discursivização do enunciador, marido de Marcela Temer, na construção da categoria referencial mulher. Busca-se, também, relacionar o campo da Sociologia dos gêneros, particularmente o feminino, com o campo da Linguística Aplicada, por meio da análise do processamento da referenciação, decorrente do modo de dizer presente na arquitetura do corpus escolhido para este estudo. 0 modelo teórico-metodológico utilizado para encadear a discussão, neste artigo, baseia-se no Interacionismo sociodiscursivo, com empréstimos do dialogismo bakhtiniano e Círculo. Pôde-se perceber que o gênero textual discursivo orienta as escolhas lexicais e ideológicas na construção referencial de conceitos e da imagem do enunciador.

\section{PALAVRAS-CHAVE}

Referenciação. Fenômenos Discursivos. Feminino. 


\section{ABSTRACT}

This is the analysis of the speech given by President, in honor of the International Women's Day, in the year 2017, with the aim of verifying the discursive strategies of the enunciator, husband Marcela Temer in the construction of the female referential category. It also seeks to relate the field of sociology of genres, particularly the feminine, to the field of applied linguistics, through the analysis of the processing of the reference, resulting from the way of saying, present in the architecture of the corpus chosen for this study. The theoretical-methodological model used to link the discussion, in this article, is based on sociodiscursive Interactionism, with loans from Bakhtinian dialogism and Circle. The discursive textual genre guides the lexical and ideological choices in the referential construction of concepts and the image of the enunciator.

\section{KEYWORDS}

Referencing. Discursive Phenomena. Female.

\section{RESUMEN}

Este es el análisis del discurso pronunciado por el presidente, en honor al día internacional de la mujer, en 2017, con el alcance para verificar estrategias de discurso del enunciador, marido de Marcela Temer en la construcción de la categoría referencial mujer. También se busca relacionar el campo de la sociología de los géneros, particularmente el femenino, con el campo de la lingüística aplicada, a través del análisis del procesamiento de la referencia, resultante de la forma de decir, presente en la arquitectura del corpus elegido para este estudio. El modelo teórico-metodológico utilizado para encadenar la discusión, en este artículo, se basa en el interaccionismo socio-discursivo, con préstamos del dialogismo Bajtíniano y del círculo. Se podría percibir que el género textual discursivo guía las opciones léxicas e ideológicas en la construcción referencial de los conceptos y la imagen del enunciador.

\section{PALABRAS LLAVE}

Referencia.Fenómenos discursivos. Femenino. 


\section{INTRODUÇ̄̃̃O}

Este ensaio visa ao estudo da forma como o conceito de mulher é construído no discurso do presidente, marido de Marcela Temer, logo no primeiro ano em que assumiu a presidência da República, após o processo de impeachment da presidenta Dilma Rousseff. Esse discurso foi pronunciado no dia 8 de março de 2017, Dia Internacional das Mulheres, no senado, em Brasília, para um público, acentuadamente, feminino.

Posto isso, destaca-se que, na contemporaneidade, após décadas de luta do movimento feminista, as mulheres brasileiras, ainda, encontram-se em situação de emancipação, embora muitos esforços tenham sido efetivados na conquista de um status próprio, autônomo e com marcas de domínio social e econômico. Nesse sentido, julga-se interessante trazer à lume o discurso do presidente da República, com vista a identificar a construção ideológica do (novo) governo em relação às questões de ordem do femininolmulher na sociedade brasileira, de modo particular as considerações que Temer faz desse domínio, também, no poder presidencial.

\section{METODOLOGIA}

A estratégia metodológica utilizada adota técnicas qualitativas, que são definidas por dados de natureza interpretativa e semântica (GONÇALVES; MEIRELLES, 2004). Para os fins, a pesquisa descritiva busca evidenciar as características, propriedades ou fatos de determinada população ou fenômenos, estabelecer relações entre variáveis ou analisar os fatos (YIN, 1981). Quanto aos meios, configura-se em categoria e corpus enunciados no discurso homenagem presidencial.

O quadro teórico-metodológico do Interacionismo sociodiscursivo conjugado com o discursivo-dialógico é interessante para verificar processos de referenciação, de modo a compreender como o referente mulher é construído pelo presidente e o efeito de sentido gerado no enunciatário. Uma abordagem interdisciplinar orienta a construção de um referente discursivo, uma vez que buscamos conjugar as análises depreendidas do discurso do presidente com um quadro teórico de vertente sociológica.

\subsection{GÊNERO TEXTUAL DISCURSIVO: O PRONUNCIAMENTO}

\section{É oportuno trazer à baila algumas informações relevantes que cuidam de apresentar elementos} característicos de um gênero textual discursivo, como o conteúdo temático, o estilo, a construção composicional que, segundo Volóchinov e Bakhtin (2017), interagem de forma indissolúvel no conjunto do enunciado e são, pela especificidade, determinados igualmente para um campo de comunicação.

Nesse sentido, esses autores defendem "que cada enunciado particular é individual, mas cada campo de utilização da língua elabora seus tipos relativamente estáveis de enunciados, os quais denominamos gêneros do discurso" (VOLÓCHINOV; BAKHTIN, 2017, p. 12).

Para analisar o discurso do presidente Temer, vale ressaltar que esse pronunciamento é protocolar, próprio de um lugar\espaço e de um enunciador constituído socialmente e ideologicamente, 
uma vez que é representante de um poder concedido pelo voto popular. Dessa forma, todo o querer dizer e o modo de dizer desse enunciador se realiza, acima de tudo, na escolha de um gênero do discurso, que pressupõe o uso da língua como objeto de trabalho, e que, por meio dessa atividade linguageira, busca produzir efeitos de sentido nos seus interlocutores, no caso do pronunciamento, no universo feminino, a partir das mulheres presentes, que ocupam relativo espaço no poder público e, decorrente da transmissãoldivulgação pública, simultânea em diversos canais midiáticos, em todos os cidadãos brasileiros.

Para efetivação desse dizer do presidente Temer, o texto oral que profere é tomado como uma unidade complexa de significação, que leva em conta a condição de produção (escrito ou improvisado), o endereçamento, interlocutores presentes, momento sócio histórico e cultural, no caso, o Dia Internacional da Mulher, construção de um governo (i)legítimo, além de outros fatores que marcam a historicidade desse lugar social.

Como produção empírica, o pronunciamento do presidente Temer constitui uma unidade significativa, marcada pela textualidade, progressão temática, informatividade, situacionalidade, elementos de coesão e coerência internas e externas ao discurso, com vista à redução de obstáculos que possam trazer prejuízo às interações linguísticas. É desse objeto empírico que elementos materiais serão reunidos para análise do processo de construção do referente mulher. 0 sentido da totalidade do enunciado, para Volóchinov e Bakhtin (2017), será chamado de seu tema, porque expressa a situação histórica que gerou o enunciado e, para Ducrot (1984), sentido é a forma de representação do objeto.

Desse pronunciamento presidencial, a reação do público é esperada pelo enunciador ao interpelar os interlocutores com informações que poderão provocar respostas tensas, moderadas ou consonantes, por meio da convocação de forças centrífugas ou centrípetas que modulam o jogo polifônico de um discurso, em especial de um discurso da esfera de um poder político, eivado de ideologia.

Para Volóchinov e Bakhtin (2017, p. 25-26), “toda compreensão da fala viva, do enunciado vivo é de natureza ativamente responsiva (embora o grau desse ativismo seja bastante diverso); toda compreensão é prenhe de resposta, e nessa ou naquela forma, obrigatoriamente, o ouvinte vira falante". Advogam, também, que cada enunciado é um "elo em uma corrente plena de outros enunciados, plena de ecos e ressonâncias as quais está ligado pela identidade da esfera de comunicação discursiva” (VOLÓCHINOV; BAKHTIN, 2017, p. 57).

Em síntese, o gênero textual-discursivo pronunciamento é um tipo de gênero de discursos secundários\segundos ou estandardizados, que aparecem nas circunstâncias de uma troca cultural (principalmente escrita), artística, científica, sociopolítica mais complexa e relativamente mais evoluída, que repousam sobre instituições sociais, que é legitimado pelo lugar do dizer e com prestígio pela função social exercida.

\subsection{CONTEXTUALIZANDO O PRONUNCIAMENTO DE MICHEL TEMER}

Para que possamos perceber o processo de referenciação do conceito mulher no pronunciamento do presidente Temer, é necessário trazer algumas informações que norteiam o posicionamento desse mandatário do governo em relação ao que fora afirmado no discurso de homenagem às mu- 
lheres. Nessa perspectiva, a referenciação não privilegia a "relação entre as palavras e as coisas, mas a relação intersubjetiva e social no seio da qual as versões do mundo são publicamente elaboradas, avaliadas em termos de adequação às finalidades práticas e às ações em curso dos enunciadores" (MONDADA, 2001, p. 9).

O (novo) governo empossado, após a destituição da então presidente Dilma Rousseff, tem como presidente o vice desta chapa, a saber, Dilma e Temer. As áreas sociais representavam os maiores desafios a serem superados pelo governo Dilma\Lula, condição que colocava esses campos em destaque, com grandes investimentos do orçamento da União, e, com destaque, também, para a presença e comando de mulheres em diferentes esferas do poder, inclusive do econômico.

Ao assumir a presidência da República, Michel Temer compôs um governo essencialmente masculino, com presença de homens no domínio das esferas financeiras, cujas decisões impactaram, diretamente, outras áreas, como educação, saúde, previdência social, entre outras. Destaca-se a presença feminina com pouca representatividade nos ministérios, limitando-se a três setores, particularmente em projetos de políticas públicas em algumas áreas sociais, com funções, reconhecidamente femininas, como na educação, saúde, assistência social, na condição de mulher professora, enfermeira, assistente social.

Esse tipo de atitude do governo nos remete ao sexismo moderno que, segundo Watkins, Kaplan, Brief, Shull, Dietz, MansWeld e Cohen (2006), é voltado para o reconhecimento da hegemonia do homem sobre a mulher. Esse sexismo se fundamenta na discriminação contra as mulheres, levando as avaliações negativas de competências e habilidades, cuja a causa dessa sub-representação em alguns cargos é devido a si próprias e não ao sistema composto por funcionários e supervisores machistas, que perpetuam a discriminação, o preconceito individual e institucional contra o gênero mulher.

O discurso durou pouco mais de dez minutos e foi proferido no Palácio do Planalto, na presença de figuras, como a Ministra dos Direitos Humanos, Luislinda Valois, a Secretária Nacional de Políticas para as Mulheres, Fátima Pelaes e a Advogada-geral da União, Grace Mendonça. A primeira dama, Marcela Temer, também esteve presente, mas falou por menos de dois minutos. Informações adicionais sobre as escolhas femininas, acima citadas, geram alguns fatos curiosos e que, de algum modo, interpelam avaliações no modo de dizer do presidente (no pronunciamento).

Nesse sentido, é necessário considerar que a secretária nacional de políticas para as mulheres, Fátima Pelaes, é do PMDB, partido do presidente, evangélica (realiza cultos diários no ambiente de trabalho) e contra o aborto, condições que contribuem na sustentação de um discurso machista, próprio da sociedade brasileira e legitimado pelo presidente Temer.

A esposa do presidente, Marcela, que também discursou, foi miss Campinas, iniciou o relacionamento com o presidente Michel Temer quando tinha 18 anos, ele com mais de 60 anos e encontram-se casados há mais de 10 anos, têm um filho, cujo nome é também Michel. Esses fatos são importantes no processamento referencial da categoria mulher, como construção social, histórica e cultural, logo, ideologicamente construídos (SCOTT, 1990), em conformidade com a teoria do Círculo Bakhtiniano.

Para além de um governo masculino, muitos foram os cortes de natureza política, voltados para as políticas públicas que visavam à emancipação feminina, de modo particular à promoção da igualdade 
de gênero nos afazeres domésticos, na equiparação salarial no trabalho, nos cuidados com a saúde, em aspectos relativos à previdência social, na formação de mão de obra qualificada e outros que visam à construção de um espaço público para o feminino: educação, política, maternidadelfilhos, violência doméstica.

Esses cortes poderão levar o Brasil a não cumprir o objetivo 5 (igualdade de gênero, empoderamento de todas as mulheres e meninas), da Agenda 2030 das Nações Unidas para o desenvolvimento sustentável, devido à discriminação e violência contra as mulheres e crianças, não atingindo a igualdade de gênero, que dificulta obter um mundo pacífico, próspero e sustentável (TRIBUNAL ..., 2019).

Após a introdução dessas informações, torna-se mais fácil analisar o discurso de homenagem que Michel Temer prestou ao Dia Internacional da Mulher, no dia 8 de março de 2017, para uma bancada feminina, que lotava o Senado, em Brasília. Enaltecendo o papel da mulher, o presidente afirmou que ela é muito importante nas tarefas domésticas, na formação dos filhos e no controle dos preços de produtos nos supermercados.

Reforçou, também, por meio de exemplos de suas ações políticas, a criação de delegacias para defesa da mulher. Nesse momento, considerando o teor da fala de Temer, é possível retornar ao patriarcado, em que há uma defesa de que o lugar de mulher é na esfera privada e o homem na esfera pública (SAFFIOTI, 2015).

0 texto traz potenciais de sentidos realizados na produção do discurso, porque o discurso vem de alguém e dirige-se a alguém (ou seja, é “endereçado"), o que modula sua arquitetônica e traz em si um tom avaliativo, ao mesmo tempo em que remete a uma compreensão responsiva ativa da parte do seu interlocutor típico no qual se insere como fatores marcantes no processo de referenciação de um objeto.

Também exibe indícios (ou marcas) de gênero de modo imediato, mas não de maneira transparente e a discursividade é assim uma mediação constitutiva entre gênero e texto, ou seja, o discurso é mobilizado pelo gênero e, dessa forma, mobiliza o texto. No entanto o "eu" é reforçado a todo instante, como sintagma nominal, verbal, pronominal, preposicional, adverbial e adjetival (KOCH, 2005).

\section{RESULTADOS}

\subsection{PROCESSOS DE REFERENCIAÇÃO NO GÊNERO PRONUNCIAMENTO PRESIDENCIAL}

Nesta seção, pretende-se trazer excertos do discurso proferido pelo presidente Michel Temer, no Dia Internacional da Mulher, procurando avaliar seu modo de dizer e o efeito de sentido na geração de referentes, como: o que representa uma homenagem às mulheres, o conceito de mulher e o espaço do feminino na sociedade brasileira.

Antes, porém, é digno de nota que o gênero textual-discursivo constitui fator muito importante na estruturação de um discurso dessa natureza, próprio de uma esfera do poder, proferido por alguém constituído para esse dizer, com plena condição de se preparar para o conteúdo do dizer, a temática, as escolhas lexicais e toda forma arquitetônica e composicional que orientam o gênero discursivo pronunciamento. 
Nessa perspectiva, os exemplos ora analisados não foram escolhidos de forma aleatória, de diferentes gêneros textuais e campos sociais, e sim, contextualizados e consolidados dentro de um único discurso presidencial, nota que reforça um pressuposto de que a escolha do gênero textual discursivo é significativa no processamento da referenciação (LOPES, 2004; 2017).

Para Ducrot (1984, p. 419),

[...] desde que haja um ato de fala, um dizer, há uma orientação necessária para aquilo que não é o dizer [...] que podemos chamar "referência", chamando "referente" ao mundo ou objeto que ela pretende descrever ou transformar. 0 referente de um discurso não é assim, como por vezes se diz, a realidade, mas sim a sua realidade, isto é, o que o discurso escolhe ou institui como realidade.

Conforme anunciado, para efeito de análise, passa-se a apresentação de recortes do discurso presidencial ${ }^{3}$, que iluminam o quadro teórico-metodológico, cujas bases sustentam-se em terrenos sociais ideologicamente construídos. O pronunciamento foi dividido em três momentos, a saber: referente - Dia Internacional das Mulheres; referente - Mulher; referente - Espaço feminino.

\subsection{REFERENTE - DIA INTERNACIONAL DA MULHER}

Os discursos são atividades de enunciação em condições históricas e sociais, que torna a interação uma matriz de sentidos, ideologicamente construídos, decorrente da posição social, histórica e cultural de cada ser humano em seu contexto/realidade concreta (VOLÓCHINOV; BAKHTIN, 2017).

Nesse sentido, vale destacar que o pronunciamento, aqui, analisado, retoma questões que envolvem o processo de emancipação da mulher, haja vista que o feminismo originou-se de um ideal de igualdade e liberdade social, política e econômica entre homens e mulheres (SCAVONE, 2008) e luta contra a opressão masculina, tendo pautas específicas como sexualidade, aborto, violência, autonomia, direitos civis e políticos (PINTO, 2010). Um dos motivos que levaram a esse movimento de libertação foi o fato de as mulheres sofrerem mais com a precarização do trabalho e serem vítimas das políticas públicas (CISNE, 2014).

Esse diálogoldiscurso reflete a percepção do presidente em relação à mulher, por meio das escolhas lexicais, do repertório vocabular, coerência, enquadramento de tópico, conhecimentos partilhados, interação, efeitos de sentido e atividades cognitivas (MONDADA; DUBOIS, 2003), conforme se segue ${ }^{4}$ :
a. [...] extremamente prestigiado pela bancada feminina da Câmara e do Senado.
b. [...] revela, desde logo, a importância da recordação anual que se faz [...].
c. [...] vejo como é importante, o como são importantes, essas solenidades [...].

3 Nota: O Discurso do Presidente da República, Michel Temer, durante Cerimônia de Comemoração pelo Dia Internacional da Mulher - Brasília/DF, proferido no Palácio do Planalto, 8 de março de 2017 (BRASIL, 2017).

4 As locuções grafadas em itálico representam escolhas lexicais do enunciador Temer que nos permitem depreender valorações ideológicas, advindas de suas concepções sócio-históricas e culturais. 
d. [...] não basta marcar no calendário o Dia da Mulher, é preciso comemorá-lo.

e. [...] comemorá-lo significa recordara luta permanente da mulher por uma posição adequada na sociedade;

f. [...] eu recordo mais uma vez, só para dizer do absurdo e, muitas vezes, da nossa história, que a mulher só começou a votar pelos idos de 30, 32 [...].

Por meio dessa informação histórica, é interessante contextualizar o sufrágio universal no Brasil, decorrente de uma pequena participação das mulheres que constituiu uma bancada feminina na atualidade, como resultado da primeira onda do movimento feminino e a primazia do sexismo.

A primeira onda ocorreu na Inglaterra, a partir da organização das mulheres em lutar por seus direitos civis e políticos básicos, como o voto. 0 voto foi concedido às mulheres no Reino Unido, em 1918. No entanto dois fatos marcaram esse primeiro momento, que foram as sufragistas mulheres sendo presas e fazendo greve de fome e a morte da feminista Emily Davison, que se jogou em frente ao cavalo do Rei e morreu em 1913.

No Brasil, houve movimento semelhante ao Reino Unido, com a participação da ativista e bióloga Bertha Luz, que retornou do exterior em 1910 e iniciou a luta em favor do voto. 0 direito ao voto ocorreu no ano de 1932, com a promulgação do Novo Código Eleitoral Brasileiro. O fato brasileiro que marcou esse período foi o movimento das operárias (costureiras, chapeleiras e de outras classes similares) com ideologia anarquista (PINTO, 2010; BRANDT; LAVARDA; LOZANO, 2017).

g- [...] Ihes deu o direito a voto, o direito mínimo, que é de participar. A mulher representa, e representava, no passado, $50 \%$ da população brasileira. E, sem embargo disso, o fato é que $50 \%$ estava excluída.

h- [...] quero dizer às colegas, às mulheres, aos senhores e às senhoras, a todos que eu fico muito, digamos assim, orgulhoso por sediar neste momento um encontro que recorda o Dia da Mulher.

i- [...] não foram apenas palavras, mas viram pelos gestos tomados pelo ministro da Saúde, que houve gestos concretos. Ou seja, gestos executivos pela assinatura dos atos que ele aqui decretou.

Pelas marcações em itálico na construção do referente Dia Internacional da Mulher, pode-se depreender certas escolhas sintagmáticas em que predominam índices de avaliação ( $\mathrm{KOCH}, 2005)$, por meio de adjetivações feitas por Temer, como evento extremamente prestigiado; importante recordação anual; importante solenidade; comemoração; recordação pelos discursos e palavras pronunciadas; momento de encontro para recordar, são meras estratégias de argumentações que não têm o propósito de persuadir e nem a intenção de fazer que o locutário adira à estratégia programada (AMOSSY, 2011).

Logo, definições superficiais, artificiais e desnaturalizadas de um momento histórico mundial, que nos remete a (re)pensar programas e políticas públicas que têm como finalidade a emancipação da mulher na sociedade pós-moderna, principalmente, em busca de sua condição civil.

Essa situação pode ser explicada da seguinte forma: a baixa representação feminina nos espaços públicos de poder institucional condiz com a responsabilidade das mulheres no espaço privado, o ma- 
chismo manifesto e dissimulado na sociedade latina, o assédio sexual e moral no ambiente laboral, sendo estes alguns desafios sociais e sociológicos que perpassam pela visão de gênero nas pesquisas empírico-teóricas, dando a visibilidade necessária às complexidades sociais, políticas e econômicas da dominação masculina (WATKINS et al., 2006; SCAVONE, 2008; SAFFIOTI, 2015).

\subsection{REFERENTE - MULHER}

Para o referente mulher, pode-se afirmar, preliminarmente, que "tudo o que é ideológico possui um significado, e remete a algo situado fora de si mesmo. Em outros termos, tudo o que é ideológico é um signo. Sem signos, não existe ideologia” (VOLÓCHINOV; BAKHTIN, 2017, p. 31). Posto isso, a situação da mulher de subalternidade e desvalorização é resultante de uma construção sócio-histórica em uma sociedade patriarcal (SAFFIOTI, 2015).

Na esfera privada, a mulher é responsável pela garantia da reprodução, propiciando a produção em menor custo e, na esfera pública, é percebida como desvalorizada, subordinada, explorada, devido aos baixos salários e sem prestígio no mundo produtivo (WATKINS et al. 2006; CISNE, 2015).

I. [...] depois do discurso emocionado da [ministra] Luislinda, de todos, enfim, dizer da importância da mulher e da luta permanente que a mulher vem fazendo ao longo do tempo no Brasil e no mundo.

II. [...] aqui e fora do Brasil [...] a mulher é tratada como se fosse uma figura de segundo grau quando, na verdade, ela deve ocupar o primeiro grau em todas as sociedades.

III. Eu digo isso com a maior tranquilidade [...].

IV. [...] porque eu tenho absoluta convicção [...].

V. [...] até por formação familiar [...].

VI. [...] e por estar ao lado da Marcela [...].

VII. [...] o quanto a mulher faz pela casa, o quanto faz pelo lar, o quanto faz pelos filhos.

Nesses excertos do discurso do presidente Temer, percebe-se a dominação masculina e a busca de uma mulher ideal, como a referente Marcela, cujo espaço doméstico compõe a ideologia masculina, como o lugar ideal para a mulher com a função de cuidadora (SAFFIOTI, 2015). Indaga-se para qual mulher, pois na segunda onda feminina, em 1960, as mulheres passaram a questionar a diferença sexual inata e a fazer uma crítica à ausência da mulher nas teorias sociológicas tradicionais, como o funcionalismo (divisão sexual do trabalho, papéis femininos e masculinos).

Nessa onda, percebe-se a perda do poder da igreja, mudanças relevantes em relação ao direito ao próprio corpo, à sexualidade (lançamento da pílula anticoncepcional, primeiro nos Estados Unidos e, posteriormente, na Alemanha), à divisão de tarefas e à continuidade da luta da primeira onda (PINTO, 2010).

VIII. [...] portanto, se a sociedade, de alguma maneira vai bem [...].

IX. [...] quando os filhos crescem, é porque tiveram uma adequada educação e formação em suas casas.

$\mathrm{X}$. E, seguramente, isso quem faz não é o homem, isso quem faz é a mulher. 
Esses excertos, acima, demonstram a referenciação de mulher construída nos limites do espaço doméstico, locus idealizado que subestima a capacidade feminina. Portanto, a desconstrução da identidade feminina como frágil, intuitiva, abnegada, altruísta, dócil, sensível é uma tentativa de demonstrar sua singularidade não contrapondo as relações de poder, visto que a identidade é manifestada pelos discursos que ordenam as características fragmentadas, que levam à feminilidade, que a universaliza e a unifica, induzindo à discriminação (ROCHA-COUTINHO, 2004).

\section{$\mathrm{XI}$. Ninguém mais é capaz de indicar os desajustes, por exemplo, de preços em supermer- cados do que a mulher. \\ XII. Ninguém é capaz de melhor detectar as eventuais flutuações econômicas do que a mulher, pelo orçamento doméstico maior ou menor. \\ XIII. [...] a representação que antes que se fazia era uma representação política de pé quebrado. XIV. [...] força motriz mais relevante do exercício da cidadania brasileira [...].}

A visão machista, patriarcal, conservadora e retrógrada do presidente foi revelada pelas construções discursivas acima apresentadas, com destaque para as escolhas de glosas, estilo e argumentatividade ao professar o significado de mulher, em especial neste início de século XXI. Destaca-se que a subordinação da mulher e os dons ou habilidades tomadas como características femininas são apropriadas pelo capitalismo, compreendidas como dons naturais e não como trabalho, que originam baixo prestígio e desvalorização social (SAFFIOTI, 2015).

À medida que as mulheres compõem o exército de reserva do capital, por meio da execução de trabalhos domésticos, como cuidados com os filhos e atividades não remuneradas, elas ressaltam a manutenção de um sistema que as oprimem. A exploração do capital fortalece a reprodução de naturalizações que ocasionam discriminações, preconceitos e desigualdades (CISNE, 2015).

\subsection{REFERENTE - CONQUISTA DO ESPAÇO FEMININO}

Para avaliar o referente espaço feminino, é relevante afirmar que toda palavra comporta duas faces. Ela é determinada tanto pelo fato de que procede de alguém, como pelo fato de que se dirige para alguém. Ela constitui, justamente, o produto da interação do locutor e do ouvinte. Toda palavra serve de expressão em relação ao outro. Por meio da "palavra, defino-me em relação ao outro, isto é, em última análise, em relação à coletividade. A palavra é uma espécie de ponte lançada entre mim e os outros" (VOLÓCHINOV; BAKHTIN, 2017, p. 117).

Com efeito, ao perceber o processamento de referenciação, que se segue, antes, devemos ressaltar que o patriarcalismo persiste na atualidade e se faz presente na vida de diversas mulheres, mesmo se libertando de suas amarras, as mulheres acabam reproduzindo-o no dia a dia. 0 patriarcado naturaliza as desigualdades de gênero, devido às relações de poder, que são hierarquizadas e desiguais, e atendem aos interesses da classe dominante (SAFFIOTI, 2015; COSTA, 2018).

Destaca-se, neste texto, que gênero é uma construção de sentidos socioculturais produzidos para a explicação sobre as diferenças sexuais, tais sentidos mostram que tais relações de poder são assimétricas e 
desiguais (SCOTT,1990; 1994). Essas informações são importantes para compreender as interações verbais que decorrem de um dizer, de alguém e que se dirige a outro falante, também, oriundo de uma sociedade, com valores próprios e coletivos, condição que ajuda a recuperar sentido no modo de dizer de outrem.

[...] ao longo do tempo, devo registrar com grande satisfação, que a mulher foi conseguindo o seu espaço.

[...] quando criei a primeira Delegacia da Mulher, parece um fato extraordinário, não é?

[...] era uma consequência natural da luta das mulheres e até conto muito rapidamente como isso se deu.

[...] comigo logo surgiu a ideia interessante de algo que não tem, ou não tinha, e não tem, nenhum custo orçamentário.

Por que que eu não coloco uma ou duas delegadas mulheres, três, quatro escrivãs, 15, 20 investigadoras para atender a mulher?

[...] teve tanto sucesso, ministro Imbassahy, que a primeira delegada da mulher, logo depois, foi eleita deputada estadual, tamanha repercussão que se verificou, e eleita, naturalmente, pelas mulheres.

[...] quando voltei a ser secretário da Segurança, tempos depois, havia praticamente mais de 90 delegacias da Mulher no estado de São Paulo e no Brasil. É um reconhecimento, portanto, da posição da mulher no cenário nacional.

[...] quando as constituições anteriores diziam todos são iguais perante a lei. A Constituinte de 88 decretou: homens e mulheres são iguais em direitos e deveres.

É interessante registrar que nas escolhas do locutor Temer, em relação ao referente espaço feminino, ele tende a priorizar informações alusivas à segurança pública, de forma a contemplar a mulher, vítima de violência doméstica, fato que nos leva a pensar em que tipo de emancipação feminina está presente no discurso de quem está no comando de um país, como o Brasil? É inacreditável a forma como trata da criação de delegacias da mulher, com naturalidade de quem não se assusta com a mulher, ainda, lutando pelos seus direitos de ser gente, de não ser agredida por familiares, parceiro, marido!

Akpinar-Sposito (2013), reforçando esse pensamento, diz que as mulheres foram criadas para o espaço privado (maior peso voltado para vida pessoal e família) do que para sua carreira, induzindo baixa credibilidade pelos pares e sentimento de baixo comprometimento com as organizações. Mas, na verdade, o sexismo está presente em todas as esferas e se manifesta de forma destrutiva nas organizações (WATKINS et al., 2006).

No entanto, o condicionamento masculino foi recompensado para proteger o poder em dicotomia das mulheres para rejeitar o poder. As mulheres tendem a ter maior tempo médio dedicado ao cuidado com os filhos e vida doméstica que os homens (PIRES et al., 2016).

[...] é um longo trajeto histórico que vem revelando a presença importantíssima da mulher [...]um dos primeiros pilares do Plano Nacional de Segurança Pública, lançado muito recentemente, é exatamente o combate ao feminicídio e à violência contra a mulher. Nós estamos até cuidando de criar um fundo de combate à violência contra a mulher. 
[...] estamos fortalecendo a Central de Atendimento à Mulher em Situação de Violência, que é o 180.

[...] digo, com toda a franqueza, isso tudo é fruto do movimento das mulheres [...] movimento muito entusiasmado, muito persistente, muito consistente, muito argumentativo até, das mulheres brasileiras.

Conforme antecipado, mais uma vez, percebe-se que o presidente acredita que o referente espaço feminino está diretamente relacionado com a segurança física da mulher, ainda tentando se esquivar de agressões, como uma espécie de segunda categoria, usando palavras pronunciadas neste discurso, pelo presidente Temer. Ademais, a violência contra a mulher é uma realidade assustadora, principalmente em sociedades machistas, tipicamente patriarcais (SAFFIOTI, 2015).

Esse tema vem sendo discutido desde a terceira onda feminina, na década de 1990, que ampliou a discussão das ondas anteriores e do feminismo em si, buscou as demandas individuais oprimidas, como as mulheres negras. 0 movimento converge para um processo de profissionalização pela criação de Organizações Não-Governamentais (ONG), visando aprovar medidas preventivas para as muIheres e buscar maior participação na política. 0 foco central era a mulher vítima de violência, sobretudo a violência doméstica.

Decorrente dessa realidade, foi aprovada a Lei Maria da Penha (Lei n. 11.340, de 7 de agosto de 2006), para a prevenção e combate à violência contra mulher (PINTO, 2010; COSTA, 2011; BRANDT et al., 2017).
E da compreensão dos homens, vamos dizer assim [...].
[...] no particular, daquelas que participam dos movimentos sociais, daquelas que estão no Legislativo, que se constituem na voz natural das eleitoras em todo o Brasil.
[...] ao longo do tempo as senhoras, as mulheres, deram uma colaboração extraordinária ao nosso sistema.
[...] hoje, como as mulheres participam em intensamente de todos os debates [...].
[...] vou até tomar a liberdade de dizer que na economia também, a mulher tem uma gran- de participação.
[...] hoje, graças a Deus, as mulheres, sem embargo das dificuldades, têm uma possibili- dade de empregabilidade que não tinham no passado.

A empregabilidade está relacionada com a condição do indivíduo em está ocupado no mercado de trabalho formal. Ressalta-se a importância dessa ocupação mediante a precariedade do trabalho vivenciada nos últimos anos com a terceirização e informalização (HELAL, 2005; 2007), sendo uma preocupação constante dos não empregados para a economia.

[...] significa também que a mulher, além de cuidar dos afazeres domésticos, vai vendo um campo cada vez mais largo para o emprego.

[...] hoje homens e mulheres são igualmente empregados. Com algumas restrições ainda.

[...] a gente vê em muitas reportagens, das mais variadas, como a mulher hoje ocupa um 
espaço executivo de grande relevância. O número de mulheres que comandam empresas, que comandam diretorias, é imenso.

Embora o presidente professe um discurso, afirmando que a empregabilidade feminina tem sido um avanço em seu governo e na sociedade atual, ainda é baixa a participação feminina nos cargos de gestão no Brasil, que, segundo o Instituto Brasileiro de Geografia e Estatística (IBGE, 2018), no ano de 2016, somente 39,1\% ocupavam esses cargos. Esse enunciado provoca uma reação responsiva, pois é histórico o fato de que as mulheres se deparam com o teto de vidro nas empresas (YAP; KONRAD, 2009; BAZAZO; NASSEEF; MUKATTESH et al., 2017; ARAÚJO; VASCONCELOS, 2018).

O número de mulheres que hoje está no Legislativo e tendo uma atuação extraordinária [...] criei a Procuradoria Parlamentar da Mulher. E, sobremais, ainda estabeleci que uma deputada teria assento, não é Elcione, teria assento na reunião de líderes, para ter voz e voto.

Segundo o IBGE (2018), a presença feminina na política, no ano de 2017, correspondia a 10,5\% na Câmara dos Deputados e, no senado, somente 16\% no Brasil e, no mundo, 23,6\%. No Brasil, foi devido à obrigatoriedade de cotas, sendo $30 \%$ no mínimo e, no máximo, $70 \%$ de candidaturas de cada sexo, por cada partido ou coligação partidária, de acordo com a Lei n.12.034 de 29 de setembro de 2009. E nos cargos ministeriais somente 7,1\% (IBGE, 2018).

[...] pouco a pouco, mas neste momento cada vez mais rapidamente, a mulher vai ocupando um espaço cada vez mais significativo, mais expressivo e mais enaltecedor da sociedade no nosso Brasil.

[...] o Brasil conta com as mulheres [...].

[...] tem a mais absoluta conviç̧ão de que a força motriz mais relevante do exercício da cidadania brasileira está nas mulheres.

Para encerrar esta análise, vale destacar o teor machista na integralidade do discurso de Temer, por meio das formas arquitetônicas e composicionais ${ }^{5}$ como estruturou o seu dizer, das escolhas de todo o léxico empregado na apresentação dos argumentos que homenageia a mulher, embora o efeito de sentido tenha gerado muita tensão entre os interlocutores. Essa situação demonstra como o sexismo e o racismo estão impregnados nas organizações, devido às subjetividades dos gestores e outros empregados. Representa ainda o contexto cultural que foi criado, pois é filho de libanês.

5 No ensaio "O problema do conteúdo, do material e da forma na criação literária (1924)" discute a questão entre forma composicional e forma arquitetônica, abordando como a forma arquitetônica se relaciona com o conteúdo. Bakhtin (1998, p. 25) insiste em estabelecer a diferença entre forma composicional do gênero e formas arquitetônicas, atribuindo à primeira o caráter de estabilidade, "teleológico", "utilitário", - embora "inquieto" - disponível para realizar "a tarefa arquitetônica". Já, as formas arquitetônicas "[...] são as formas dos valores morais e físicos do homem estético, as formas da natureza enquanto seu ambiente, as formas do acontecimento no seu aspecto de vida particular, social, histórica, etc.; todas elas são aquisições, realizações, não servem a nada, mas se auto satisfazem tranquilamente; são as formas da existência estética na sua singularidade. [...] A forma arquitetônica determina a escolha da forma composicional". 
Afinal, a referenciação do presidente para o modelo de "mulher”, branca e classe média, é capaz de ocupar certos papéis, que pode / quer ficar em casa, desempenhando tarefas domésticas somente ... ou, é possível que ele tenha se dirigido ao contingente feminino.

\subsection{ATITUDE RESPONSIVA DOS INTERLOCUTORES}

Nesta sequência, julgamos de grande pertinência, para somar argumentos nessa análise, trazer alguns comentários evocados por diferentes interlocutores, no Brasil e em outros países, como reação ao discurso de Temer. Em Benveniste (1989), encontramos explicação que norteia a leitura que os interlocutores abstraíram do discurso presidencial, em especial quando afirma que ocorre uma ruptura entre o sistema codificado da língua para o processo de enunciação, uma vez que esse deslocamento do domínio do objeto instituído da linguística do sistema para o discurso (enunciação): entrada decisiva do sujeito e da subjetividade no tratamento da significação.

No domínio do semiótico, o signo é base significante da língua, material necessário da enunciação, reconhecido pelos membros da comunidade linguística, podendo evocar as mesmas associações e oposições. No domínio semântico, o modo de significância é engendrado pelo discurso. A análise linguística desvincula-se do signo como objeto único, no sentido saussuriano, para abrigar-se no discurso (SAUSSURE, 1972).

A linguagem deixa de ser vista como expressão do pensamento e passa a ser considerada como um modo de ação. A relação com a realidade acontece na língua em funcionamento. A linguagem submete o mundo à sua própria organização, conforme se apresentam os comentários que se seguem, retirados do Jornal El País, Rede CNM, The New York Times, Telegraph, The Independent, Frankfurter Allgemeine ${ }^{6}$.

"Que imbecil esse Michel Temer. Quem faz supermercado é mulher? Na minha casa eu que faço há muitos anos», escritor Marcelo Rubens Paiva. Para a CNN, Michel Temer foi merecidamente criticado por "elogiar as habilidades das mulheres no supermercado" em um dia que se celebra a luta histórica das mulheres por direitos. A rede de televisão americana também disse que "o presidente foi acusado de ser machista por milhões de brasileiros nas redes sociais".

El País falou sobre o discurso de Temer em reportagem intitulada Temer reduz papel da mulher à casa e é alvo de protestos nas redes sociais (MARREIRO, 2017). O The New York Times também repercutiu o assunto, com um texto chamado "Brasileiro Temer irrita mulheres com elogio às suas habilidades no supermercado". O texto lembra que Temer assumiu em maio com uma equipe toda masculina. “Agora, seu gabinete de 28 membros tem duas mulheres", diz.

O jornal britânico Telegraph lembra que Temer já é impopular entre as mulheres por seu papel no impeachment da primeira presidente mulher do Brasil, por ter abolido o Ministério das Mulheres,

6 Embora reconheçamos as normas ABNT para citações textuais curtas e longas, optamos por apresentá-las sem o recuo recomendado para citações acima de 3 linhas. Dessa forma, a opção atende ao caráter estético do texto. Ademais, como as informações foram extraídas de publicações abertas a todo tipo de público, julgou-se desnecessário tratar de questões éticas pela apresentação de declarações sem a devida autorização dos autores das falas. 
Igualdade Racial e Direitos Humanos e por ter assumido o poder com um gabinete inteiramente masculino. 0 também britânico The Independent disse que a fala de Temer foi 'sexista' ao lembrar que "o presidente brasileiro parabenizou as mulheres por "tomarem conta da casa, educarem as crianças e checarem preços no supermercado"'.

Especialistas em trabalho doméstico, crianças, compras: Michel Temer quis fazer um cumprimento às brasileiras, no Dia das Mulheres. "Mas a tentativa do presidente brasileiro saiu pela culatra”, apontou o jornal alemão Frankfurter Allgemeine (DISCURSO..., 2017). Temer exalta a importância da mulher no supermercado e isso não é coisa do Sensacionalista. “É um discurso que nos recoloca no que é, para o mundo machista, o nosso único lugar: em casa, cuidando dos filhos. E justo no dia que seria ideal para celebrar que lugar de mulher é onde ela quiser", diz Milena Prado, economista do Dieese.

A fala foi tão surpreendente e a reação irada das mulheres tão previsível que deu até no New York Times: “Temer do Brasil irrita mulheres com elogio às suas habilidades no supermercado", debochou o diário. "Logo no Dia Internacional da Mulher! Ele perdeu a chance, por exemplo, de defender a convenção sobre a igualdade de remuneração entre homens e mulheres da OIT, que o Brasil ratificou, mas está longe de cumprir", diz Milena Prado, economista do Dieese.

Completa, dizendo que "É papel de um presidente promover essa igualdade". Temos experimentado mudanças, mas o estupro, a violência contra as mulheres, continua em níveis altíssimos. $E$, no mundo do trabalho, "os salários ainda são $20 \%$ menores do que os dos homens na mesma posição, ainda que o nível de escolarização feminino hoje seja maior do que o masculino”, diz Milena Prado, economista do Dieese.

Os comentários apresentados confirmam nossa discussão neste artigo, uma vez que reforçam a postura machista e retrógrada do presidente Michel Temer em relação ao processamento da referenciação sobre a mulher, homenagem ao Dia Internacional da Mulher e ao domínio do espaço feminino.

Essas manifestações verbais proferidas pelos importantes jornais internacionais, além da opinião de uma interlocutora que se sensibilizou pelo discurso anacrônico do presidente Temer, demonstram, em tempos de reconhecimento de direitos humanos e sociais de forma globalizada, o quanto a construção do referente mulher pode representar nas políticas públicas governamentais, em especial na política brasileira.

\section{CONSIDERAÇÕES FINAIS}

Por meio deste estudo, pôde-se perceber que o gênero pronunciamento permite ao enunciador, dadas as condições sócio-históricas e culturais da esfera social característica desse gênero e na qual é proferido, fazer suas escolhas lexicais, bem como em operadores argumentativos e modalizadores, e escolhas ideológicas que pretende apresentar ao seu auditório.

Essas condições de produção nos levam a assegurar que não há neutralidade ao optar por uma expressão, uma vez que o falante privilegia alguns aspectos de textualização em detrimento de outros, com vistas a processar uma referência, e, de compartilhar conhecimento por meio da interação verbal. 
Trata-se de uma construção de três referentes muito próximos, como Homenagem ao Dia Internacional da Mulher, Mulher e espaço feminino no discurso proferido por Michel Temer, em 2017. Essa subdivisão apresentada nos permitiu notar que, nos três tópicos, a construção do referente macro mulher revelou um modo de pensar retrógrado, patriarcal e machista do presidente Temer. A homenagem ao Dia internacional da mulher não passa de um evento que recorda as conquistas da mulher, reconhecendo sua importância na família, em casa e na educação dos filhos. 0 espaço feminino ainda é um lócus que exige muita luta da mulher para demarcar seu território e habitá-lo.

Somos da opinião que a conclusão de maior alcance a tirar deste estudo refere-se à importância do processamento referencial na construção de sentido\ compreensão textual. A contextualização do enunciador, do discurso, do auditório sugere grande relevância na explicaçãolconstrução de um referente, indicada pela introdução do assunto, condução, retomada, apontada e retomada no interior do discursol texto. Destaca-se que este discurso do presidente Temer, proferido no Dia Internacional da Mulher, pode ser analisado com outras lentes dentro do processo de referenciação e argumentação, como exemplo, a construção do ethos ${ }^{7}$ do presidente e as predicações empregadas na arquitetura do seu modo de dizer.

\section{REFERÊNCIAS}

AKPINAR-SPOSITO, C. Women in management research: theoretical perspectives.11. 4EME FrancoTch`eque Trends in International Business, Lyon, France, 2013.

AMOSSY, R. Argumentação e análise do discurso: perspectivas teóricas e recortes disciplinares. Tradução de Eduardo Lopes Piris e Moisés Olímpio Ferreira. EID\&A - Revista Eletrônica de Estudos Integrados em Discurso e Argumentação, n. 1, p. 129-144, 2011.

ARAÚJO, F. S.; VASCONCELLOS, B. M. Vivenciando o ser mulher em uma mina de carvão. Revista Estudos Feministas, v. 26, n. 1, p. e44967, jan. 2018.

BAKHTIN, M. M. O problema do conteúdo, do material e da forma na criação literária. In: Questões de literatura e de estética: A teoria do romance. Trad. Aurora F. Bernadini e outros. São Paulo: Hucitec, 1998. p. 13-70.

BAZAZO, I.; NASSEEF, M.A.; MUKATTESH, B.; KASTERO, D.; AL- HALLAQ, M.A. Assessing the glass ceiling effect for women in tourism and hospitality. Journal of Management and Strategy, v. 8, n. 3, p. 51-66, jun. 2017.

BENVENISTE, É. Problemas de lingüística geral II. Trad. Eduardo Guimarães. 3 ed., Campinas, SP, Pontes, II, 1989.

$7 \mathrm{Na}$ teoria da argumentação de base aristotélica, o ethos consiste na edificação do eu do enunciador, locutor do discurso, como base para construção de sua credibilidade e da competência de seus argumentos usados para convencer o seu público. 
BRANDT, J. Z.; LAVARDA, R. A. B.; LOZANO, M. A. S. P. L. Estratégia como-prática social para a construção da perspectiva de gênero nas políticas públicas em Florianópolis. Revista de Administração Pública, Rio de Janeiro, v. 51, n. 1, p. 64-87, jan.-fev. 2017.

BRASIL. Lei Maria da Penha. Lei n. 11.340/2006. Coíbe a violência doméstica e familiar contra a mulher. Presidência da República, 2006. Brasília, 8 ago. 2006. Diário Oficial da União, Seção 1, p.1-4.

CISNE, M. Feminismo e consciência de classe no Brasil. São Paulo: Cortez, p. 276, 2014.

CISNE, M. Gênero, divisão sexual do trabalho e serviço social. 2. ed. São Paulo: Outras expressões. p.144, 2015.

COSTA, A. A. A. El movimiento feminista en Brasil: dinámicas de una intervención política. Hojas de Warmi, v. 16, p. 1-40, 2011.

COSTA, M. N. Transformando o patriarcado? O papel da luta feminista na reconfiguração das categorias marxistas. Trans/Form/Ação, Marília, v. 41, n. 3, p. 125-144, jul. 2018.

DUCROT, O. Referente. In: Enciclopédia Einaudi: linguagem e enunciação, v. 2, p. 418- 438, Lisboa: Imprensa Nacional, Casa da Moeda, 1984.

GONÇALVES, C. A.; MEIRELLES, A. M. Projetos e relatórios de pesquisa em administração. São Paulo: Atlas, 2004.

HELAL, D. H. Flexibilização organizacional e empregabilidade individual:

proposição de um modelo explicativo. Cadernos EBAPE-BR, v. 3, n.1, p.1-15, março 2005.

HELAL, Diogo Henrique et al. Empregabilidade gerencial no Brasil. RAC-Eletrônica, Curitiba, v. 1, n. 2, p. 1-19, 2007.

IBGE - Instituto Brasileiro de Geografia e Estatística. Estudos e Pesquisas: Informação Demográfica e Socioeconômica, n.38. Disponível em: https://biblioteca.ibge.gov.br/index.php/biblioteca-catalog o?view=detalhes\&id=288941. Acesso em: 5 fev. 2018.

KOCH, I. G. V. Referenciação e orientação argumentativa. In: KOCH, I. G. V.; MORATO, E.; BENTES, A. C. Referenciação e discurso. São Paulo: Contexto, 2005. p. 33-52.

LOPES, M. Â. P. T. Referenciação e gênero textual - atividades sócio-discursivas em interação. In: MACHADO, I. L.; MELLO, R. de (Org.). Gêneros: reflexão em análise do discurso. Belo Horizonte: NAD/POSL in, FALE/UFMG, 2004. p. 205-219. 
LOPES, M. Â. P. T. Eventos de leitura no espaço acadêmico - representações sociais no processo de referenciação do gênero charge. In: BARROS, E. M. D.; STORTO, L. J. (Org.) Gêneros do jornal e ensino: práticas de letramentos na contemporaneidade. São Paulo: Pontes, 2017, p. 241-264.

MARREIRO, Flávia. Temer reduz papel da mulher à casa e é alvo de protestos nas redes sociais. El País, São Paulo, 9 mar 2017. Disponível em: https://brasil.elpais.com/brasil/2017/03/08/ politica/1489008097_657541.html. Acesso em: 5 fev. 2018.

MONDADA, L. Gestíon du topique et organization de la conversation. Cadernos de Estudos Linguísticos, v. 41, p. 7-36, 2001.

MONDADA, L.; DUBOIS, D. Construção dos objetos de discurso e categorização: uma abordagem dos processos de referenciação. In. CAVALCANTE, M. M.; RODRIGUES, B. B.; CIULLA, A. (Org.). Referenciação, SP: Contexto, 2003. p.17-52.

PINTO, C. R. J. Feminismo, história e poder. Revista Sociologia Política, v. 18, n. 36, p.15-23, 2010.

PIRES, M. R. G. M.; FONSECA, R. M. G. S.; PADILLA, B. Politicy of care in the criticism towards gender stereotypes. Revista Brasileira de Enfermagem, v. 69, n. 6, p. 1156-1162, 2016.

DISCURSO de Temer no Dia da Mulher vira vergonha internacional. Pragmatismo Político, 10 mar. 2017. Disponível em: https://www.pragmatismopolitico.com.br/2017/03/discurso-de-temer-no-diada-mulher-vira-piada-internacional.html. Acesso em: 8 fev. 2018.

ROCHA-COUTINHO, M. L. Novas opções, antigos dilemas: mulher, família, carreira e relacionamento no Brasil. Temas em Psicologia da SBP, v. 12, n. 1, p. 1-17, 2004.

SAFFIOTI, H. I. B. Gênero, patriarcado e violência. In: BONGIOVANI, H. L.; SAFFIOTTI, H. I. B. 2. ed. São Paulo: Fundação Perseu Abramo, 2015.

SAUSSURE, F. A natureza do signo linguístico. In: SAUSSURE, Ferdinand. Curso de linguística geral. São Paulo: Cultrix, 1972. p. 79-84.

SCAVONE, L. Estudos de gênero: uma sociologia feminista? Estudos Feministas, v. 16, n.1, p.1 73-186, 2008.

SCOTT, J. W. Preface a gender and politics of history. Cadernos Pagu, v. 3, p. 11-27, 1994.

SCOTT, J. W. Gender: a useful category of historical analysis. Educação \& Realidade, v. 20, n. 2, p. 71-99, 1990. 
TRIBUNAL de Contas da União. Relatório de auditoria. Grupo II- Classe V- Plenário. TC 005.355/2018-3, 2019. Auditoria aponta deficiências de coordenação e articulação em políticas do governo pela igualdade de gênero e empoderamento feminino. 2019.

VOLÓCHINOV, V.; BAKHTIN, M. Marxismo e filosofia da linguagem: problemas fundamentais dos métodos sociológicos na ciência da linguagem. Tradução, notas e glossário de Sheila Grillo e Ekaterina Vólkova Américo. São Paulo: Editora 34, 2017.

WATKINS, M. B.; KAPLAN, S.; BRIEF, A. P. et al. Does it pay to be a sexist? The relationship between modern sexism and career outcomes. Journal of Vocational Behavior, v. 69, n. 3, p. 524-537, 2006.

YAP, M.; KONRAD, A. M. Gender and racial differentials in promotions: is there a sticky floor, a midlevel bottleneck, or a glass ceiling? Industrial Relations, v. 64, n. 4, p. 593-619, 2009.

YIN, R. K. The Case Study Crisis: some answers. Administrative Science Quartely, Cornell University, v. 26, p. 58-65,1981. 
1 Mestre em Administração - Centro Universitário UMA; Doutoranda no Programa de Pós-Graduação em Administração / Pontifícia Universidade Católica de Minas Gerais; MBA em administração de organizações hospitalares e serviços de saúde - FGV; Especialista em assistência farmacêutica pelo SUS - UFSC e em Administração de serviços de saúde e saúde pública; Farmacêutica -bioquímica - UFMG; Membro do Núcleo de Estudos em Recursos Humanos e Relações de Trabalho - NERHRUT. E-mail: claudiahgv@gmail.com

2 Mestre em Línguística / Pontifícia Universidade Católica de Minas Gerais; Doutoranda no Programa de Pós-Graduação em Linguística e Língua Portuguesa/ Pontifícia Universidade Católica de Minas Gerais; Especialista em Metodologia do Ensino Superior; Graduada em Pedagogia e em Letras; Experiência no ensino superior, particularmente na área de produção textual acadêmica. E-mail: gilcecastro@terra.com.br

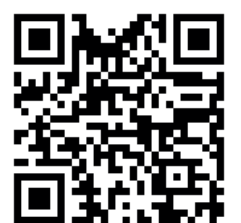

A autenticidade desse artigo pode ser conferida no site https://periodicos. set.edu.br

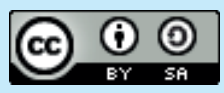

Este artigo é licenciado na modalidade acesso abertosob a Atribuição-Compartilhalgual CC BY-SA

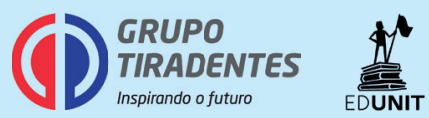

